\title{
Metabolic and vascular determinants of impaired cognitive performance and abnormalities on brain magnetic resonance imaging in patients with type 2 diabetes
}

\author{
S. M. Manschot • G. J. Biessels • H. de Valk • A. Algra • \\ G. E. H. M. Rutten • J. van der Grond • L. J. Kappelle • \\ on behalf of the Utrecht Diabetic Encephalopathy \\ Study Group
}

Received: 19 April 2007 / Accepted: 19 June 2007 / Published online: 2 September 2007

(C) Springer-Verlag 2007

\begin{abstract}
Aims/hypothesis The determinants of cerebral complications of type 2 diabetes are unclear. The present study aimed to identify metabolic and vascular factors that are associated with impaired cognitive performance and abnormalities on brain MRI in patients with type 2 diabetes.

Methods The study included 122 patients and 56 controls. Neuropsychological test scores were divided into five cognitive domains and expressed as standardised $z$ values. Brain MRI scans were rated for white matter lesions (WML), cortical and subcortical atrophy, and infarcts. Data on glucose metabolism, vascular risk factors and micro- and macrovascular disease were collected.
\end{abstract}

Electronic supplementary material The online version of this article (doi:10.1007/s00125-007-0792-z) contains details of the Utrecht Diabetic Encephalopathy Study Group, which are available to authorised users.

S. M. Manschot $(\bowtie) \cdot$ G. J. Biessels $\cdot$ L. J. Kappelle

Rudolf Magnus Institute of Neuroscience,

Department of Neurology, G03.228, University Medical Center, P.O. Box 85500, 3508 GA Utrecht, The Netherlands

e-mail: S.M.Manschot@umcutrecht.nl

H. de Valk

Department of Internal Medicine, University Medical Center,

Utrecht, The Netherlands

A. Algra · G. E. H. M. Rutten

Julius Center for Health Sciences and Primary Care,

University Medical Center,

Utrecht, The Netherlands

J. van der Grond

Department of Radiology, Leiden University Medical Center,

Leiden, The Netherlands
Results Patients with type 2 diabetes had more cortical ( $p<$ $0.001)$ and subcortical $(p<0.01)$ atrophy and deep WML $(p=$ 0.02 ) than the control group and their cognitive performance was worse. In multivariate regression analyses within the type 2 diabetes group, hypertension $(p<0.05)$ and a history of vascular events $(p<0.01)$ were associated with worse cognitive performance, while statin use was associated $(p<0.05)$ with better performance. Retinopathy and brain infarcts on MRI were associated with more severe cortical atrophy (both $p<0.01)$ and statin use with less atrophy $(p<0.05)$. Insulin level and brain infarcts were associated with more severe WML and statin use with less severe WML (all $p<0.05$ ).

Conclusions/interpretation Type 2 diabetes is associated with modest impairments in cognition, as well as atrophy and vascular lesions on MRI. This 'diabetic encephalopathy' is a multifactorial condition, for which atherosclerotic (macroangiopathic) vascular disease is an important determinant. Chronic hyperglycaemia, hyperinsulinaemia and hypertension may play additional roles.

Keywords Brain atrophy · Brain MRI .

Cerebral complications - Cognitive performance .

Diabetic encephalopathy · Metabolic risk factors .

Neuropsychological investigation - Type 2 diabetes mellitus .

Vascular risk factors $\cdot$ White matter lesions

$\begin{array}{ll}\text { Abbreviations } \\ \text { CIMT } & \text { carotid intima-media thickness } \\ \text { DWML } & \begin{array}{l}\text { deep white matter lesions } \\ \text { fluid-attenuating inverse recovery } \\ \text { FLAIR }\end{array} \\ \text { HOMA-IR } & \begin{array}{l}\text { homeostasis model assessment of insulin } \\ \text { resistance } \\ \text { magnetic resonance imaging }\end{array}\end{array}$

Abbreviations

CIMT carotid intima-media thickness

DWML deep white matter lesions

FLAIR fluid-attenuating inverse recovery

MRI magnetic resonance imaging 
PWML periventricular white matter lesions

WML white matter lesions

\section{Introduction}

Diabetes mellitus is associated with slowly progressive changes in the brain [1]. Neuropsychological studies show that patients with type 2 diabetes mellitus have mild to moderate impairments in attention and executive functioning, information processing speed and memory (for reviews see [2, 3]). Patients with type 2 diabetes also show changes on brain magnetic resonance imaging (MRI), such as cortical and hippocampal atrophy $[4,5]$. We have recently shown that cognitive dysfunction in patients with type 2 diabetes was associated with white matter lesions (WML), (silent) brain infarcts and to a lesser extent with atrophy [6].

The determinants of changes in cognition and abnormalities on brain MRI of patients with type 2 diabetes are uncertain [2]. Some studies report associations with hypertension [3, 4, 7, 8], but this was not supported by others [5, 9, 10]. Associations between impaired cognition and chronic hyperglycaemia have also been noted [9]. Studies on other diabetic complications may provide leads for potentially relevant determinants. Complications like nephropathy, retinopathy and neuropathy are thought to be due to hyperglycaemia-induced microangiopathy [11, 12], with additional involvement of hypertension and macrovascular disease [13-15]. Since atherosclerosis and hypertension are established risk factors for age-related cognitive decline and brain MRI changes in the general population [16-19], we hypothesised that the combined effects of atherosclerotic macrovascular disease, chronic hyperglycaemia and hypertension are involved in the development of cognitive impairments in patients with type 2 diabetes.

The aim of the present study was to identify possible metabolic and vascular determinants of cognitive dysfunction and changes on brain MRI in patients with type 2 diabetes. Given the uncertainty about these determinants, an exploratory design was chosen. A detailed neuropsychological examination and brain MRI were obtained from a large cross-sectional sample of type 2 diabetes patients and related to different measures of glucose metabolism, vascular risk factors, microvascular complications and macrovascular disease.

\section{Methods}

Participants The Utrecht Diabetic Encephalopathy Study aims to identify determinants of cognitive impairment in patients with diabetes [6]. Therefore, patients were not selected for the presence or absence of diabetic complications, co-morbid conditions (e.g. hypertension) or exposure to other risk factors (e.g. smoking). For inclusion patients had to be 55 to 80 years of age, functionally independent and speakers of Dutch, with a minimal diabetes duration of 1 year. Exclusion criteria for all participants were: a psychiatric or neurological disorder that could influence cognitive functioning; a history of alcohol or substance abuse and dementia; and, for the control group, a fasting blood glucose $\geq 7.0 \mathrm{mmol} / 1$ [20]. Participants with a history of stroke who were still fully functionally independent were classified as eligible. To increase statistical power for within-group analyses in the type 2 diabetes group, twice as many patients as controls were enrolled.

Overall, 122 patients with type 2 diabetes (age 5680 years) and 56 controls (age 57-78 years) were included in the present study. Patients were recruited through their general practitioners; controls were spouses or acquaintances of the patients. Groups were comparable for age, sex and educational level. The study was approved by the local medical ethics committee and each participant signed an informed consent form. All participants underwent a 2 day protocol, which included brain MRI, a neurological and neuropsychological examination, retinal photography and ultrasonography of the carotid arteries. Fasting blood and urine samples were collected and blood pressure was recorded. In one control person and two type 2 diabetes patients it was not possible to perform the neuropsychological examination. Similarly, MRIs could not be obtained in five controls and nine type 2 diabetes patients, mostly due to MRI contraindications (claustrophobia, pacemaker).

Neuropsychological examination The neuropsychological examination tapped the major cognitive domains in verbal and non-verbal ways. Eleven tasks were administered in a fixed order, taking about $90 \mathrm{~min}$ to complete. These tasks were divided into five cognitive domains, as described previously [6]: (1) attention and executive functioning; (2) information processing speed; (3) memory; (4) abstract reasoning; and (5) visuoconstruction. For analysis the test scores were standardised into $z$ scores for each of the five domains, based on the means of the whole group. The mean performance from each participant across the domains is expressed as the composite cognitive $z$ score.

Premorbid IQ was assessed with the Dutch version of the National Adult Reading Test. To control for possible effects of mood disturbances or affective disorders a Beck depression inventory [21] was performed.

Brain MRI The MRI investigation (1.5 T; Philips Medical Systems, Best, the Netherlands) consisted of an axial T1weighted and an axial T2 and T2 fluid-attenuating inverse recovery (FLAIR) scan (TR/TE/TI: 6000/100/2000, field of 
view $230 \mathrm{~mm}$, matrix $180 \times 256$, slice thickness $4.0 \mathrm{~mm}$, contiguous, 38 slices).

WML were rated according to the Scheltens scale [22] with slight modifications [6]. Periventricular WML (PWML) were rated on a severity scale (0-2) at the frontal and occipital horns and the body of the lateral ventricle on both sides (sum score 0-12). For the rating of deep (subcortical) WML (DWML) the brain was divided into six regions: frontal, parietal, occipital, temporal, basal ganglia and infra-tentorial. Per region the size and number of WML were rated on a scale ranging from 0 to 6 . The total score thus ranged from 0 to 36 .

Cortical atrophy was evaluated by the frontal interhemispheric fissure ratio and the Sylvian fissure ratio [23]. Subcortical atrophy was evaluated by the bifrontal ratio and by the bicaudate ratio [23]. These ratios were converted to $z$ scores: a cortical atrophy $z$ score (mean of $z$ frontal fissure ratio and $z$ Sylvian fissure ratio) and a subcortical atrophy $z$ score (mean of $z$ bicaudate ratio and $z$ bifrontal ratio).

All MRI scans were rated by two investigators (S. M. Manschot and G. J. Biessels) blinded for presence or absence of diabetes or other characteristics. In case of disagreement of more than 1 point on the WML scales in a particular region or more than $5 \mathrm{~mm}$ (actual size) on any of the atrophy measurements ( $2 \mathrm{~mm}$ for fissure widths), a consensus reading was held ( $0 \%$ of PWML, $4 \%$ of DWML and $4 \%$ of atrophy ratio readings were thus affected). In all other cases the readings of both raters were averaged.

Diabetes characteristics and glucose metabolism A standardised questionnaire addressed medical history, medication use, diabetes duration and the life-time occurrence of severe hypoglycaemic episodes (defined as episode of hypoglycaemia severe enough to require the assistance of another person, hospitalisation or emergency room visit). BMI was calculated as weight divided by height square.

Blood was drawn by venepuncture to assess $\mathrm{HbA}_{1 \mathrm{c}}$, fasting glucose and insulin levels. Insulin resistance was estimated with the homeostasis model assessment of insulin resistance (HOMA-IR). The HOMA-IR is calculated as fasting glucose $(\mathrm{mmol} / \mathrm{l}) \times$ fasting insulin $(\mathrm{mU} / \mathrm{l}) / 22.5$ [24] Because insulin was expressed in $\mathrm{pmol} / \mathrm{l}$ we used the formula fasting glucose $(\mathrm{mmol} / \mathrm{l}) \times$ fasting insulin $(\mathrm{pmol} / \mathrm{l}) /$ $(22.5 \times 6.945)$ [24].

Vascular risk factors Blood pressure was measured at home at nine fixed time points during the day with an automatic blood pressure machine (705CP; Omron, Mannheim, Germany). These measurements were averaged. In the primary analysis hypertension was defined as a mean systolic blood pressure $>160 \mathrm{mmHg}$ or a mean diastolic pressure $>95 \mathrm{mmHg}$ or the use of antihypertensive medication. In a second analysis cut-off values for systolic and diastolic blood pressure of 140 and $90 \mathrm{mmHg}$ were used.

Smoking habits were classified as 'current' and 'past or never'. Total cholesterol, HDL-cholesterol, LDL-cholesterol and triacylglycerol were assessed in a fasting venous blood sample.

Microvascular disease Following mydriasis with phenylephrine and tropicamide, single-field photographs were taken of both eyes with a 50-degree retinal camera (Zeiss FF 450, Carl Zeiss B.V., Sliedrecht, the Netherlands), centred on the macula. Retinopathy was rated on slides, according to the diabetic retinopathy severity scale (grades 1-7) as used in the Wisconsin Epidemiologic Study of Diabetic Retinopathy [25]. Photocoagulated eyes were rated at grade 5 or higher (severe non-proliferative diabetic retinopathy). Ratings were performed by two investigators, blinded to patient characteristics. In case of disagreement (2\%), a third investigator was involved and a consensus was made. Retinopathy was defined as a grade of 1.5 or higher.

Neuropathy was rated with the Toronto Clinical Neuropathy Scoring System [26], with a slight modification. A sensory test for temperature was not performed, so that the maximum score was 18 points (severe polyneuropathy) instead of 19. A score of $0-5$ indicated no neuropathy, 68 indicated mild neuropathy, 9-11 moderate neuropathy and $\geq 12$ severe neuropathy. Neuropathy was defined as a score of $\geq 6$.

Urine was collected overnight. Albuminuria was defined as microalbuminuria (albumin $0.03-0.25 \mathrm{~g} / \mathrm{l}$ ) or macroalbuminuria (albumin $0.25 \mathrm{~g} / 1$ or positive protein dipstick test).

Macrovascular disease Several composite measures of macrovascular disease were defined. 'Any peripheral arterial disease' was defined as current complaints of intermittent claudication (assessed with the Rose questionnaire [27]) or a history of surgery or endovascular treatment for arterial disease of the legs or the abdominal aorta. 'Ischaemic heart disease' was defined as a history of myocardial infarction or surgery or endovascular treatment for coronary artery disease. 'Any vascular event' was defined as a history of myocardial infarction or stroke, or a history of operative or endovascular treatment for coronary, carotid or peripheral (legs, abdominal aorta) artery disease.

Brain infarcts were rated on brain MRI, by location (cortical and subcortical), size (lacunar $[<1.5 \mathrm{~cm}]$ or large) and number. A lesion was considered an infarct if it was hypo-intense on T1 and FLAIR images and if its appearance was unlike a perivascular space.

Carotid intima-media thickness (CIMT) was measured in both common carotid arteries as described previously [28] with an ATL Ultramark 9 (Advanced Technology Labora- 
tories, Bothell, WA, USA) equipped with a $10-\mathrm{MHz}$ lineararray transducer. Scanning was performed at three different longitudinal projections (anterior-oblique, lateral and posterior-oblique). The CIMT was measured in a $1 \mathrm{~cm}$ section proximal to the beginning of the dilatation of the carotid bulb in all three projections, in both carotid arteries. CIMT was calculated as the average of these six measurements. CIMT readings were not available in six type 2 diabetes patients and one person in the control group.

Statistical analysis The differences between patients and the control group were examined with $t$ test for means, Mann-Whitney $U$ was used for non-parametric data and $\chi^{2}$ test for proportions. In the text and tables, data are shown as mean \pm SD or proportions, unless stated otherwise.

Within the type 2 diabetes population, cognition (five domains) and brain MRI findings (cortical and subcortical atrophy $z$ scores, PWML, DMWL and infarcts) were related to the different measures of glucose, insulin and lipid metabolism, and to microvascular complications and macrovascular disease by linear or logistic regression analyses, adjusting for age, sex and estimated IQ. In order to limit the number of analyses the "composite cognitive $z$ score' was used as the primary cognitive outcome measure in the regression analyses. For significant associations, post hoc tests were performed per domain. Secondary analyses were performed with information processing speed, the domain most markedly affected by type 2 diabetes. The results were essentially the same as for the composite cognitive $z$ score (data not shown).

In the regression analyses, $\mathrm{B}$ values $>0$ indicate that a variable is associated with more severe MR abnormalities; for cognition $\mathrm{B}$ values $<0$ indicate that a variable is associated with more pronounced performance impairments. For the between and within-group analyses, $p<$ 0.05 was considered statistically significant. All variables that reached a significance level of $p \leq 0.1$ in the adjusted univariate risk factor analyses were included in a multivariate model that also included age, sex and estimated IQ.

\section{Results}

Participant characteristics The age, sex, level of education and estimated IQ in the groups were comparable (Table 1).

Detailed neuropsychological and MRI data have been reported previously [6]. In short, performance of patients with type 2 diabetes was worse than that of the control group across all five cognitive domains, with statistically significant differences on attention and executive functioning (difference mean $z$ scores 0.23 [95\% CI 0.03, 0.43]; $p=$
Table 1 Participant characteristics

\begin{tabular}{|c|c|c|}
\hline Characteristic & $\begin{array}{l}\text { Type } 2 \text { diabetes } \\
\text { group }\end{array}$ & Control group \\
\hline Participants $(n)$ & 122 & 56 \\
\hline Sex (male/female) & $62 / 60$ & $25 / 31$ \\
\hline Age (years) & $66.0 \pm 5.8$ & $65.1 \pm 5.2$ \\
\hline Level of education $(1-7)^{\mathrm{a}}$ & $4(3-5)$ & $4(3-5)$ \\
\hline Estimated premorbid IQ & $99 \pm 15$ & $101 \pm 14$ \\
\hline Diabetes duration (years) ${ }^{\mathrm{b}}$ & $8.7 \pm 6.1$ & \\
\hline \multicolumn{3}{|l|}{ Diabetes treatment $(\%)$} \\
\hline Diet & 10 & \\
\hline Oral medication alone & 61 & \\
\hline Insulin ${ }^{\mathrm{b}}$ & 29 & \\
\hline $\mathrm{HbA}_{1 \mathrm{c}}(\%)^{\mathrm{b}}$ & $6.9 \pm 1.2^{* *, \mathrm{~d}}$ & $5.5 \pm 0.3$ \\
\hline Fasting glucose levels $(\mathrm{mmol} / \mathrm{l})^{\mathrm{b}}$ & $8.6 \pm 2.9^{* *}$ & $5.5 \pm 0.6$ \\
\hline Fasting insulin levels $(\mathrm{pmol} / \mathrm{l})^{\mathrm{b}, \mathrm{c}}$ & $\begin{array}{l}120 \pm 110^{* *}, \mathrm{e} \\
(n=82)\end{array}$ & $\begin{array}{l}76 \pm 50 \\
(n=54)\end{array}$ \\
\hline HOMA-IR ${ }^{b, c}$ & $6.6 \pm 6.4^{* *, \mathrm{f}}$ & $2.6 \pm 1.8$ \\
\hline BMI $\left(\mathrm{kg} / \mathrm{m}^{2}\right)^{\mathrm{b}}$ & $28.1 \pm 4.4$ & $27.3 \pm 5.3$ \\
\hline
\end{tabular}

Data are given as number or percentage (as indicated), mean $\pm \mathrm{SD}$ or ranges

$* * p<0.01$ for type 2 diabetes vs control group

${ }^{\mathrm{a}}$ Level of education was expressed in seven categories [49]

${ }^{\mathrm{b}}$ Entered as explanatory variable in the regression analyses within the type 2 diabetes group

${ }^{\mathrm{c}}$ Only from participants who were not treated with insulin and did not have antibodies against insulin

Statistically significant associations within the type 2 diabetes group: with composite cognitive $z$ scores $-{ }^{d} p<0.05$; with MRI abnormalities_- $p<0.01,{ }^{\mathrm{f}} p<0.05$

$0.02)$, information processing speed $(0.40[0.17,0.63] ; p=$ $0.001)$ and memory $(0.20[0.05,0.36] ; p=0.01)$. Patients with type 2 diabetes had more pronounced cortical atrophy (difference mean $z$ scores 0.62 [95\% CI 0.33, 0.91]; $p<$ $0.001)$ and subcortical atrophy $(0.38[0.07,0.68] ; p=0.01)$. They also had more severe DWML (controls, median [range]: $5[0,18]$; type 2 diabetes: $7[0.5,27.5] ; p=0.02)$, but PWML severity in the two groups was similar (control: 6 [4, 10]; type 2 diabetes: $6[3,12] ; p=0.13$ ). Patients with type 2 diabetes also had more (silent) cerebral infarcts than controls (type 2 diabetes 22/113, control 4/54; $p=0.06$ ).

Glucose metabolism $\mathrm{HbA}_{1 \mathrm{c}}$, fasting glucose and insulin levels were higher (all $p<0.01$ ) in patients with type 2 diabetes than in the control group. BMI was similar in both groups. Only a small proportion (6\%) of type 2 diabetes patients had ever experienced a severe hypoglycaemic event (Table 1).

In the regression analyses within the type 2 diabetes group, $\mathrm{HbA}_{1 \mathrm{c}}$ levels were significantly related to cognition (composite $z$ score: $\mathrm{B}$ [per \% $\mathrm{HbA}_{1 \mathrm{c}}$ ]: $-0.07[-0.14,0] p=$ 0.047; post hoc per domain: information processing speed: B [per \% $\mathrm{HbA}_{1 \mathrm{c}}$ ]: -0.15 [95\% CI: $\left.-0.27,-0.2\right], p=0.02$; abstract reasoning: $\mathrm{B}:-0.15[-0.29,-0.01], p=0.04)$. Elevated fasting insulin levels and HOMA-IR were related 
Table 2 Vascular risk factors

\begin{tabular}{|c|c|c|}
\hline Characteristic & $\begin{array}{l}\text { Type } 2 \text { diabetes } \\
\text { group }(n=122)\end{array}$ & $\begin{array}{l}\text { Control group } \\
(n=56)\end{array}$ \\
\hline Mean arterial pressure $(\mathrm{mmHg})^{\mathrm{a}}$ & $103 \pm 11^{*, \mathrm{~b}}$ & $98 \pm 10$ \\
\hline Pulse pressure $(\mathrm{mmHg})^{\mathrm{a}}$ & $65 \pm 15^{*}$ & $59 \pm 16$ \\
\hline Hypertension $(\%)^{\mathrm{a}}$ & $73 * *$ & 34 \\
\hline Antihypertensive drugs (\%) & $70 * *$ & 32 \\
\hline Current smoking $(\%)^{\mathrm{a}}$ & 22 & 14 \\
\hline Total cholesterol $(\mathrm{mmol} / \mathrm{l})^{\mathrm{a}}$ & $5.0 \pm 0.9 * *$ & $5.8 \pm 1.1$ \\
\hline HDL-cholesterol $(\mathrm{mmol} / \mathrm{l})^{\mathrm{a}}$ & $4.3 \pm 1.2$ & $4.4 \pm 1.5$ \\
\hline Triacylglycerol $(\mathrm{mmol} / \mathrm{l})^{\mathrm{a}}$ & $1.9 \pm 1.0$ & $1.6 \pm 1.1$ \\
\hline Lipid-lowering drugs $(\%)^{\mathrm{a}}$ & $54 * *, \mathrm{c}$ & 21 \\
\hline
\end{tabular}

Data are given as percentage or mean $\pm \mathrm{SD}$

${ }^{*} p<0.05, * * p<0.01$ for type 2 diabetes vs control group

${ }^{a}$ Entered as explanatory variable in the regression analyses within the type 2 diabetes group

${ }^{\mathrm{b}} p<0.05$ for association with more severe MRI abnormalities

${ }^{c} p<0.05$ for reverse association

to increased DWML severity (B [per $10 \mathrm{pmol} / 1$ insulin]: $0.14[0.04,0.26], p=0.009$; B [HOMA-IR]: 0.21 [0.04, $0.39], p=0.02$ ).

Vascular risk factors Table 2 shows that patients with type 2 diabetes had higher systolic blood pressure $(p<0.01)$ and pulse pressure $(p<0.05)$ than controls. They also had hypertension more often $(p<0.01)$. Total cholesterol was lower in the type 2 diabetes group $(p<0.01)$, but the proportion of individuals taking lipid-lowering drugs was higher in that group $(p<0.01)$. There were no statistically significant differences between type 2 diabetic patients and the control group in the proportion of participants who smoked or had dyslipidaemia (Table 2).

In the regression analyses within the type 2 diabetes group there were no statistically significant associations with the composite cognitive $z$ score. Non-significant trends $(p \leq 0.10)$ were observed for associations between both hypertension and current smoking and impaired cognitive performance (hypertension $\mathrm{B}:-0.19[-0.38,0], p=0.053$; smoking B: $-0.21[-0.43,0], p=0.051)$, and between the use of lipid-lowering drugs and better performance (B: 0.15 $[-0.03,0.32], p=0.10)$. Reanalysis with cut-off values for hypertension of $140 / 90 \mathrm{mmHg}$ made the association with the composite cognitive $z$ score less strong. Mean arterial pressure was associated with more severe PWML (B [per $10 \mathrm{mmHg}$ ]: 0.28 [0.03, 0.53], $p=0.03$ ). The use of lipidlowering drugs (statins in all but one patient) was associated with less severe MRI abnormalities (PWML: B: $-0.68[-1.25,-0.12], p=0.02$; cortical atrophy: B: -0.36 $[-0.69,-0.03], p=0.03)$. These effects were not affected by additional adjustment for the actual cholesterol levels (Table 2).
Microvascular disease In 20 patients with type 2 diabetes and 8 control individuals it was not possible to perform retinal photographs. Mostly due to logistical reasons, overnight urine samples could not be obtained from 21 diabetic patients and 13 controls. Patients with type 2 diabetes had more retinopathy and neuropathy than the control group (both $p<0.01$ ). Although albuminuria was more common in the type 2 diabetic than in the control group, this difference was not statistically significant (Table 3).

In the regression analyses within the type 2 diabetes group, there were no statistically significant associations with the composite cognitive $z$ score. Retinopathy was associated with more pronounced cortical atrophy (B: 0.48 [0.11, 0.85], $p=0.01$ ) (Table 3).

Macrovascular disease Patients with type 2 diabetes were more likely to have had intermittent claudication $(p<0.01)$ or a history of ischaemic heart disease $(p<0.01)$. There was no difference between the two groups in the CIMT (Table 4).

In the regression analyses within the type 2 diabetes group, a history of 'any vascular event' and the presence of brain infarcts on MRI were associated with an impaired composite cognitive $z$ score as follows: (1) vascular event: composite $z$ score B: $-0.25(-0.44,-0.05), p=0.01$; post hoc per domain: information processing speed B: -0.46 $(-0.80,-0.12), p=0.008$; and memory B: $-0.23(-0.41$, $-0.06), p=0.01$; (2) infarct on MRI: composite $z$ score B:

Table 3 Microvascular disease

\begin{tabular}{lll}
\hline Characteristic & $\begin{array}{l}\text { Type 2 diabetes } \\
\text { group }(n=122)\end{array}$ & $\begin{array}{l}\text { Control group } \\
(n=56)\end{array}$ \\
\hline $\begin{array}{l}\text { Retinopathy (diabetes } \\
n=112 \text {; control } n=48)^{\mathrm{a}}\end{array}$ & $37(33)^{* *, \mathrm{~b}}$ & $1(2)$ \\
$\begin{array}{l}\text { Background } \\
\text { Severe non-proliferative }\end{array}$ & 33 & 1 \\
Neuropathy $^{\mathrm{a}}$ & 4 & \\
Mild neuropathy $_{\text {Moderate neuropathy }}$ & 25 & $7(13)$ \\
Severe neuropathy & 18 & 7 \\
Albuminuria (diabetes & 4 & 0 \\
$n=101 ;$ control $n=43)^{\mathrm{a}}$ & $16(16)$ & 0 \\
Microalbuminuria & 9 & $3(7)$ \\
Macroalbuminuria & 7 & 3 \\
Any microvascular disease & $72(59)^{* *,}$ & $11(20)$ \\
\hline
\end{tabular}

Data are given as values (percentage)

${ }^{* *} p<0.01$ for type 2 diabetes vs control group

${ }^{a}$ Entered as explanatory variable in the regression analyses within the type 2 diabetes group

${ }^{\mathrm{b}} p<0.05$ for association with MRI abnormalities

${ }^{\mathrm{c}}$ Includes all patients with albuminuria, neuropathy or retinopathy 
Table 4 Macrovascular disease

\begin{tabular}{|c|c|c|}
\hline Characteristic & $\begin{array}{l}\text { Type } 2 \text { diabetes } \\
\text { group }(n=122)\end{array}$ & $\begin{array}{l}\text { Control group } \\
(n=56)\end{array}$ \\
\hline $\begin{array}{l}\text { Any peripheral arterial } \\
\text { disease }^{\mathrm{a}}\end{array}$ & $18(15)^{* *}$ & 0 \\
\hline $\begin{array}{l}\text { Claudicatio } \\
\text { intermittens }\end{array}$ & $14(11)^{* *}$ & 0 \\
\hline $\begin{array}{c}\text { Vascular surgery } \\
\text { femoral artery }\end{array}$ & $4(3)$ & 0 \\
\hline $\begin{array}{l}\text { Vascular surgery } \\
\text { (AAA) }\end{array}$ & $3(3)$ & 0 \\
\hline $\begin{array}{l}\text { Ischaemic heart } \\
\text { disease }^{\mathrm{a}}\end{array}$ & $23(19)^{* *, b}$ & $2(4)$ \\
\hline Myocardial infarction & $15(12)^{*}$ & $1(2)$ \\
\hline CABG & $13(11)^{*}$ & $1(2)$ \\
\hline Brain infarct on $\mathrm{MRI}^{\mathrm{a}}$ & $22(20)^{*, b, c}$ & $4(8)$ \\
\hline $\begin{array}{l}\text { History of brain } \\
\text { infarct }^{\mathrm{a}}\end{array}$ & $7(6)$ & $2(4)$ \\
\hline Carotid surgery $^{\mathrm{a}}$ & $2(2)$ & $1(2)$ \\
\hline Any vascular event ${ }^{a}$ & $33(27)^{* *, b, c}$ & $4(7)$ \\
\hline CIMT $^{\mathrm{a}}$ & $0.093 \pm 0.018$ & $0.092 \pm 0.023$ \\
\hline
\end{tabular}

Data are given as value (percentage) or mean $\pm \mathrm{SD}$

AAA, abdominal aortic aneurysm; CABG, coronary artery bypass grafting ${ }^{*} p<0.05,{ }^{* *} p<0.01$ for type 2 diabetes vs control group

${ }^{a}$ Entered as explanatory variable in the regression analyses within the type 2 diabetes group

Statistically significant associations: with MRI abnormalities ${ }^{\mathrm{b}} p<0.05$; with impaired cognition ${ }^{\mathrm{c}} p<0.05$

$-0.28(-0.50,-0.06), p=0.01$; post hoc per domain: information processing speed B: $-0.77(-1.14,-0.39), p<$ 0.001; and abstract reasoning B: $-0.41(-0.82,0.01), p=$ 0.06 . A history of 'any vascular event' was also associated with more pronounced DWML (B: $2.0[0,4.1], p=0.05$ ) and with an increased occurrence of infarcts on MRI (odds ratio: 2.9 [1.1, 7.9], $p=0.04$ ). Patients with a (silent) infarct on MRI tended to have more pronounced PWML (B: 0.7 $[0,1.4], p=0.06)$ and cortical atrophy (B: 0.51 [0.10, 0.92], $p=0.02$ ) relative to type 2 diabetes patients without infarcts on MRI (Table 4).

Exclusion of patients with a history of stroke attenuated the association between 'any vascular event' and the cognitive $z$ score, but not that between 'any vascular event' and DWML.

Multivariate analysis For the majority of risk factors the values of the standardised regression coefficients $B$ were similar in the single risk factor and multivariate models, indicating that interaction between factors was limited. Values for $\beta$ for individual factors varied between 0.15 and 0.30 , indicative of modest associations (Table 5).

In the multivariate model, hypertension and a history of vascular events were associated with worse cognitive performance and statin use with better performance.
Retinopathy and brain infarction on MRI were associated with more severe cortical atrophy and statin use with less atrophy. A higher insulin level was associated with more DWML, brain infarction on MRI with more PWML and statin use with less PWML. Overall, macrovascular disease (history of macrovascular events or infarct on MRI) were most consistently associated with the different outcome measures (Table 5).

\section{Discussion}

Patients with type 2 diabetes had more cortical and subcortical atrophy and more DWML than control participants and their overall performance in the five cognitive domains was worse. As expected, patients with type 2 diabetes had more microvascular complications, more macrovascular (atherosclerotic) disease and more hypertension than the control group. In multivariate regression analyses within the type 2 diabetes group, hypertension and a history of vascular events were associated with worse cognitive performance, while statin use was associated with better performance. Retinopathy and brain infarcts on MRI were associated with more severe cortical atrophy and statin use with less atrophy. Insulin level and brain infarcts were associated with more severe WML and statin use with less severe WML.

Cognitive function in patients with type 2 diabetes has been studied extensively (for reviews see [2, 3]). Performance in the domains verbal memory and information processing speed, and probably also executive functioning and non-verbal memory, is moderately impaired. Our results are in keeping with these findings. Thus far, relatively few studies have specifically addressed brain MRI abnormalities in patients with type 2 diabetes. In agreement with our observations, modest cortical and subcortical atrophy and symptomatic or asymptomatic infarcts have been found more often in type 2 diabetes patients than in control individuals [4, 5, 29]. Results of previous studies on the association between type 2 diabetes and WMLs are less consistent [30]. This might be due to the study populations involved and the use of relatively insensitive WML rating scales [30].

Chronic hyperglycaemia might be a determinant of cerebral changes in patients with type 2 diabetes. In the present study, $\mathrm{HbA}_{1 \mathrm{c}}$ levels were related to the composite cognitive $z$ score, but only in de univariate analysis. Moreover, retinopathy, which is generally considered to be a consequence of chronic exposure to hyperglycaemia [11], was related to cortical atrophy. Previous studies on cognition in patients with type 2 diabetes have also reported an association with $\mathrm{HbA}_{1 \mathrm{c}}$ levels $[2,9,31]$. The relation 
Table 5 Multivariate risk factor analyses within the type 2 diabetes group

\begin{tabular}{|c|c|c|c|}
\hline & Single factors $\beta(95 \% \mathrm{CI})$ & Full model $\beta(95 \% \mathrm{CI})$ & Final model $\beta(95 \% \mathrm{CI})$ \\
\hline \multicolumn{4}{|l|}{ Cognition } \\
\hline Age & & $-0.30(-0.44,-0.16)^{* * *}$ & $-0.29(-0.43,-0.14)^{* * *}$ \\
\hline Sex & & $-0.12(-0.24,0.02)$ & \\
\hline Estimated IQ & & $0.65(0.50,0.79)^{* * *}$ & $0.65(0.50,0.80)^{* * *}$ \\
\hline $\mathrm{HbA}_{1 \mathrm{c}}$ & $-0.14(-0.28,-0.002)^{*}$ & $-0.11(-0.25,0.02)$ & \\
\hline Hypertension & $-0.14(-0.26,0.002)$ & $-0.12(-0.26,0.01)$ & $-0.14(-0.27,-0.001)^{*}$ \\
\hline Current smoking & $-0.14(-0.29,0.001)$ & $-0.15(-0.29,-0.02)^{*}$ & $-0.14(-0.27,0.001)$ \\
\hline Lipid-lowering drugs & $0.12(-0.02,0.26)$ & $0.17(0.03,0.31)^{*}$ & $0.17(0.03,0.31)^{*}$ \\
\hline Any vascular event & $-0.18(-0.32,-0.03)^{*}$ & $-0.18(-0.32,-0.03)^{*}$ & $-0.19(-0.34,-0.05)^{* *}$ \\
\hline Brain infarct on $\mathrm{MRI}^{\mathrm{a}}$ & $-0.18(-0.32,-0.04)^{*}$ & & \\
\hline \multicolumn{4}{|l|}{ Cortical atrophy } \\
\hline Sex & & $-0.005(-0.23,0.22)$ & \\
\hline Age & & $0.35(0.18,0.52)^{* * *}$ & $0.34(0.18,0.51)^{* * *}$ \\
\hline Estimated IQ & & $-0.07(-0.24,0.10)$ & \\
\hline Lipid-lowering drugs & $-0.20(-0.37,-0.02)^{*}$ & $-0.19(-0.36,-0.03)^{*}$ & $-0.18(-0.35,-0.02)^{*}$ \\
\hline Retinopathy & $0.24(0.05,0.43)^{*}$ & $0.21(0.04,0.39)^{*}$ & $0.22(0.06,0.39)^{* *}$ \\
\hline Brain infarct on MRI & $0.22(0.04,0.39)^{*}$ & $0.23(0.06,0.40)^{* *}$ & $0.23(0.06,0.40)^{* *}$ \\
\hline \multicolumn{4}{|l|}{ DWML } \\
\hline Sex & & $0.13(-0.05,0.30)$ & \\
\hline Age & & $0.20(0.02,0.35)^{*}$ & $0.22(0.04,0.39)^{*}$ \\
\hline Estimated IQ & & $-0.14(-0.31,0.04)$ & \\
\hline Insulin level & $0.29(0.08,0.51)^{* *}$ & $0.26(0.04,0.47)^{*}$ & $0.24(0.03,0.45)^{*}$ \\
\hline Any vascular event & $0.19(-0.002,0.37)$ & $0.15(-0.03,0.34)$ & \\
\hline \multicolumn{4}{|l|}{ PWML } \\
\hline Sex & & $0.16(-0.02,0.34)$ & $0.16(-0.02,0.34)$ \\
\hline Age & & $0.25(0.07,0.43)^{* *}$ & $0.24(0.07,0.42)^{* *}$ \\
\hline Estimated IQ & & $-0.12(-0.30,0.06)$ & \\
\hline Mean arterial pressure & $0.20(0.02,0.38)^{*}$ & $0.15(-0.03,0.33)$ & $0.17(-0.004,0.35)$ \\
\hline Lipid-lowering drugs & $-0.22(-0.35,-0.001)^{*}$ & $-0.20(-0.38,-0.02)^{*}$ & $-0.18(-0.35,0.001)^{*}$ \\
\hline Brain infarct on MRI & $0.17(-0.006,0.35)$ & $0.18(0.01,0.36)^{*}$ & $0.18(0.009,0.36)^{*}$ \\
\hline
\end{tabular}

$\beta$ is the standardised regression coefficient $B$. The first column contains the values of $\beta$ for all variables that reached a significance level of a least $p=0.10$ in the univariate risk factor analyses within the type 2 diabetes patient group, adjusted for age, sex and estimated IQ. These variables were included in a multivariate model that also included age, sex and estimated IQ (second column, full model). The final model (third column) is based on backward elimination of non-significant factors. This final model shows which variables that were related to the outcome measures in the univariate model remained significantly associated with the outcome measures independently of the other factors in the full model

For cognition $\beta$ values $<0$ indicate that a variable is associated with more pronounced performance impairments; for MRI $\beta$ values $>0$ indicate that a variable is associated with more severe MRI abnormalities

$* p<0.05$

$* * p<0.01$

$* * * p<0.001$

a Because 'infarct on MRI' and 'history of any vascular event' were interrelated in the univariate analyses (see Macrovascular disease section) only 'history of any vascular event' was entered in the multivariate model

with fasting blood glucose or duration of diabetes is, however, inconsistent $[31,32]$. No previous studies have provided detailed data on the association between glycaemic control and MRI changes in type 2 diabetes. Studies in type 1 diabetes mellitus, however, have shown an association between diabetic retinopathy (as a proxy of chronic hyperglycaemia) and both brain atrophy [33, 34] and cognitive functioning [35]. There are no previous studies on the relation between insulin levels and cerebral complications in type 2 diabetes. The association with WML severity, observed by us in the present study, is of particular interest in the light of recent studies in the general population, which link insulin to vascular abnormalities and degenerative changes in the brain $[36,37]$.

Previous studies in the general population indicate that risk factors for vascular disease, such as hypertension, dyslipidaemia, increased BMI and smoking, are associated with an increased risk of cognitive decline and dementia and with brain MRI changes, including WML (e.g. [3841]). Previous studies on the modulating effect of hypertension on cognitive function in type 2 diabetes show conflicting results $[7,9,42,43]$. In the present study, hypertension was related with impaired cognitive performance and mean arterial pressure with PWML severity. To 
our knowledge, the relation between other vascular risk factors and both cognition and brain MRI in patients with type 2 diabetes has not been examined previously. The reverse association between the use of statins and both cognition and MRI findings is intriguing. Nevertheless, this observation cannot be regarded as proof of a possible treatment effect. It should be noted that the association between statin use and both cognition and age-related brain MRI changes in the general population is still being debated [44]. The present findings will need to be confirmed by further studies.

Macrovascular atherosclerotic disease appeared to be the most consistent determinant of impaired cognition and brain MRI abnormalities in the type 2 diabetes patients in the present study. We have not found any previous studies that presented detailed data on the relation between macrovascular disease and cerebral changes in people with type 2 diabetes. In the general population, however, several studies have shown that macrovascular atherosclerotic disease is associated with age-related cognitive impairment and changes in brain MRI. In a large cross-sectional study, for example, previous vascular events, presence of plaques in the carotid arteries and presence of peripheral arterial atherosclerotic disease were negatively associated with cognitive performance [17]. In another study, the association between the number of cardiovascular disease conditions and cognitive impairment appeared to show a 'dose-response' relationship [18]. With regard to brain MRI changes, a history of stroke or myocardial infarction has been associated with the presence of WML [19] and plaques in the carotid artery with PWML $[16,45]$.

The strength of our study is that we combined detailed data on cognitive function and brain MRI with detailed data on metabolic and vascular risk factor clusters, thus allowing an accurate assessment of the relation between these factors. Possible limitations include patient selection, the crosssectional design and the large number of explanatory variables addressed. With regard to patient selection, we aimed to obtain a representative sample of functionally independent patients with type 2 diabetes from the general population. Although the rather demanding testing protocol may have deterred patients with relatively severe mental or physical limitations, the prevalence of microvascular and macrovascular disease, hypertension and smoking habits, as well as the level of metabolic control in our study sample is comparable with those found in other population-based studies in the Netherlands [46-48]. To minimise the effects of lifestyle and socioeconomic factors, control participants were recruited from the direct environment of the type 2 diabetic patients. Consequently, the prevalence of risk factors such as hypertension and high BMI was higher than would be expected in the general population in the Netherlands. If anything, this would have decreased the differences in cognition and MRI ratings between the groups. The cross-sectional design of our study precludes inferences about causal relationships. Moreover, the cognitive and imaging outcome measures were probably influenced by a large number of factors, some of which are specific to type 2 diabetes mellitus (e.g. chronic hyperglycaemia, diabetes treatment) and some not (e.g. age, hypertension, atherosclerosis). Our exploratory analysis included a large number of explanatory variables, which has certain drawbacks. First, different explanatory variables might be interrelated. The relatively small regression coefficients and effect sizes affect the evaluation of these interrelations and limit statistical power. This may also explain why some of the variables that reached statistical significance in the univariate analyses dropped out of the multivariate model. Nevertheless, the multivariate analysis as presented in Table 5 does indicate which variables were the strongest independent determinants of cognition and MRI abnormalities in the model used. The second drawback is that the large number of regression analyses can lead to type I errors. Nevertheless, we feel that this first detailed study of cognition and brain MRI in type 2 diabetes patients in relation to metabolic and vascular risk factors does provide important leads that could be further evaluated in future studies. Such studies should: (1) preferably have a longitudinal design; (2) include assessment of cognition and brain MRI in relation to chronic hyperglycaemia and atherosclerotic vascular disease; and (3) allow the assessment of potential confounders (e.g. hypertension).

Type 2 diabetes is associated with modest impairments in cognition, as well as with atrophy and vascular lesions on MRI. This 'diabetic encephalopathy' is a multifactorial condition, for which atherosclerotic (macroangiopathic) vascular disease is an important determinant. Chronic hyperglycaemia, hypertension and hyperinsulinaemia may play additional roles.

Acknowledgements This research was financially supported by the Dutch Diabetes Research Foundation (grant 2001.00.023). The work of A. Tiehuis (Utrecht University) on the retinopathy rating is gratefully acknowledged.

Duality of interest The authors declare that there is no duality of interest associated with this manuscript.

\section{Reference}

1. Gispen WH, Biessels GJ (2000) Cognition and synaptic plasticity in diabetes mellitus. Trends Neurosci 23:542-549

2. Allen KV, Frier BM, Strachan MW (2004) The relationship between type 2 diabetes and cognitive dysfunction: longitudinal studies and their methodological limitations. Eur J Pharmacol 490:169-175 
3. Stewart R, Liolitsa D (1999) Type 2 diabetes mellitus, cognitive impairment and dementia. Diabet Med 16:93-112

4. Schmidt R, Launer LJ, Nilsson LG et al (2004) Magnetic resonance imaging of the brain in diabetes: the Cardiovascular Determinants of Dementia (CASCADE) Study. Diabetes 53:687-692

5. den Heijer T, Vermeer SE, van Dijk EJ et al (2003) Type 2 diabetes and atrophy of medial temporal lobe structures on brain MRI. Diabetologia 46: 1604-1610

6. Manschot SM, Brands AM, van der Grond GJ et al (2006) Brain magnetic resonance imaging correlates of impaired cognition in patients with type 2 diabetes. Diabetes 55:1106-1113

7. Elias PK, Elias MF, D'Agostino RB et al (1997) NIDDM and blood pressure as risk factors for poor cognitive performance. The Framingham Study. Diabetes Care 20:1388-1395

8. Asimakopoulou KG, Hampson SE, Morrish NJ (2002) Neuropsychological functioning in older people with type 2 diabetes: the effect of controlling for confounding factors. Diabet Med 19:311316

9. Kanaya AM, Barrett-Connor E, Gildengorin G, Yaffe K (2004) Change in cognitive function by glucose tolerance status in older adults: a 4-year prospective study of the Rancho Bernardo study cohort. Arch Intern Med 164:1327-1333

10. Luchsinger JA, Reitz C, Honig LS, Tang MX, Shea S, Mayeux R (2005) Aggregation of vascular risk factors and risk of incident Alzheimer disease. Neurology 65:545-551

11. Sheetz MJ, King GL (2002) Molecular understanding of hyperglycemia's adverse effects for diabetic complications. JAMA 288:2579-2588

12. Cameron NE, Eaton SE, Cotter MA, Tesfaye S (2001) Vascular factors and metabolic interactions in the pathogenesis of diabetic neuropathy. Diabetologia 44:1973-1988

13. Ravid M, Brosh D, Ravid-Safran D, Levy Z, Rachmani R (1998) Main risk factors for nephropathy in type 2 diabetes mellitus are plasma cholesterol levels, mean blood pressure and hyperglycemia. Arch Intern Med 158(9):998-1004

14. No authors listed (1998) Tight blood pressure control and risk of macrovascular and microvascular complications in type 2 diabetes: UKPDS 38. UK Prospective Diabetes Study Group. BMJ 317: 703-713

15. Tesfaye S, Chaturvedi N, Eaton SE et al (2005) Vascular risk factors and diabetic neuropathy. N Engl J Med 352:341-350

16. de Leeuw FE, de Groot JC, Bots ML et al (2000) Carotid atherosclerosis and cerebral white matter lesions in a population based magnetic resonance imaging study. J Neurol 247:291-296

17. Breteler MM, Claus JJ, Grobbee DE, Hofman A (1994) Cardiovascular disease and distribution of cognitive function in elderly people: the Rotterdam Study. BMJ 308:1604-1608

18. van Exel E, Gussekloo J, Houx P et al (2002) Atherosclerosis and cognitive impairment are linked in the elderly. The Leiden 85-plus Study. Atherosclerosis 165:353-359

19. Breteler MM, van-Swieten JC, Bots ML et al (1994) Cerebral white matter lesions, vascular risk factors, and cognitive function in a population-based study: the Rotterdam Study. Neurology 44:1246-1252

20. American Diabetes Association (1998) Report of the Expert Committee on diagnosis and classification of diabetes mellitus. Diabetes Care 21:S5-S19

21. Beck A, Ward C, Mendelson M, Mock J, Erbaugh J (1961) An inventory for measuring depression. Arch Gen Psychiatry 4:561-571

22. Scheltens P, Barkhof F, Leys D et al (1993) A semiquantative rating scale for the assessment of signal hyperintensities on magnetic resonance imaging. J Neurol Sci 114:7-12

23. Gomori JM, Steiner I, Melamed E, Cooper G (1984) The assessment of changes in brain volume using combined linear measurements. A CT-scan study. Neuroradiology 26:21-24
24. Matthews DR, Hosker JP, Rudenski AS, Naylor BA, Treacher DF, Turner RC (1985) Homeostasis model assessment: insulin resistance and beta-cell function from fasting plasma glucose and insulin concentrations in man. Diabetologia 28:412-419

25. Klein R, Klein BE, Magli YL et al (1986) An alternative method of grading diabetic retinopathy. Ophthalmology 93:1183-1187

26. Bril V, Perkins BA (2002) Validation of the Toronto Clinical Scoring System for diabetic polyneuropathy. Diabetes Care 25:2048-2052

27. Rose GA, Blackburn H, Gillurn RF, Prineas RJ (1982) Cardiovascular survey methods. Report of the World Health Organization. WHO, Geneva

28. Bisschops RH, Klijn CJ, Kappelle LJ, van Huffelen AC, van der Grond J (2003) Association between impaired carbon dioxide reactivity and ischemic lesions in arterial border zone territories in patients with unilateral internal carotid artery occlusion. Arch Neurol 60:229-233

29. Vermeer SE, den Heijer T, Koudstaal PJ, Oudkerk M, Hofman A, Breteler MM (2003) Incidence and risk factors of silent brain infarcts in the population-based Rotterdam Scan Study. Stroke 34:392-396

30. van Harten B, de Leeuw FE, Weinstein HC, Scheltens P, Biessels GJ (2006) Brain imaging in patients with diabetes: a systematic review. Diabetes Care 29:2539-2548

31. Perlmuter LC, Hakami MK, Hodgson-Harrington C et al (1984) Decreased cognitive function in aging non-insulin-dependent diabetic patients. Am J Med 77:1043-1048

32. Zaslavsky LM, Gross JL, Chaves ML, Machado R (1995) Memory dysfunction and autonomic neuropathy in non-insulindependent (type 2) diabetic patients. Diabetes Res Clin Pract 30:101-110

33. Wessels AM, Simsek S, Remijnse PL et al (2006) Voxel-based morphometry demonstrates reduced grey matter density on brain MRI in patients with diabetic retinopathy. Diabetologia 49:2474 2480

34. Musen G, Lyoo IK, Sparks CR et al (2006) Effects of type 1 diabetes on gray matter density as measured by voxel-based morphometry. Diabetes 55:326-333

35. Brands AM, Biessels GJ, De Haan EH, Kappelle LJ, Kessels RP (2005) The Effects of type 1 diabetes on cognitive performance: a meta-analysis. Diabetes Care 28:726-735

36. Craft S, Watson GS (2004) Insulin and neurodegenerative disease: shared and specific mechanisms. Lancet Neurol 3:169-178

37. Kernan WN, Inzucchi SE, Viscoli CM, Brass LM, Bravata DM, Horwitz RI (2002) Insulin resistance and risk for stroke. Neurology 59:809-815

38. de Leeuw FE, de Groot JC, Oudkerk M et al (1999) A follow-up study of blood pressure and cerebral white matter lesions. Ann Neurol 46:827-833

39. Elias MF, Wolf PA, D’Agostino RB, Cobb J, White LR (1993) Untreated blood pressure level is inversely related to cognitive functioning: the Framingham Study. Am J Epidemiol 138:353364

40. Whitmer RA, Sidney S, Selby J, Johnston SC, Yaffe K (2005) Midlife cardiovascular risk factors and risk of dementia in late life. Neurology 64:277-281

41. Qiu C, Winblad B, Fratiglioni L (2005) The age-dependent relation of blood pressure to cognitive function and dementia. Lancet Neurol 4:487-499

42. Hassing LB, Hofer SM, Nilsson SE et al (2004) Comorbid type 2 diabetes mellitus and hypertension exacerbates cognitive decline: evidence from a longitudinal study. Age Ageing 33:355-361

43. Fontbonne A, Berr C, Ducimetiere P, Alperovitch A (2001) Changes in cognitive abilities over a 4-year period are unfavorably affected in elderly diabetic subjects: Results of the Epidemiology of Vascular Aging Study. Diabetes Care 24:366-370 
44. Shobab LA, Hsiung GY, Feldman HH (2005) Cholesterol in Alzheimer's disease. Lancet Neurol 4:841-852

45. Pico F, Dufouil C, Levy C et al (2002) Longitudinal study of carotid atherosclerosis and white matter hyperintensities: the EVA-MRI cohort. Cerebrovasc Dis 14:109-115

46. Costa LA, Canani LH, Lisboa HR, Tres GS, Gross JL (2004) Aggregation of features of the metabolic syndrome is associated with increased prevalence of chronic complications in type 2 diabetes. Diabet Med 21:252-255

47. Spijkerman AM, Henry RM, Dekker JM et al (2004) Prevalence of macrovascular disease amongst type 2 diabetic patients detected by targeted screening and patients newly diagnosed in general practice: the Hoorn Screening Study. J Intern Med 256:429-436

48. Goudswaard AN, Stolk RP, Zuithoff P, Rutten GE (2004) Patient characteristics do not predict poor glycaemic control in type 2 diabetes patients treated in primary care. Eur J Epidemiol 19:541545

49. Hochstenbach J, Mulder T, van Limbeek J, Donders R, Schoonderwaldt H (1998) Cognitive decline following stroke: a comprehensive study of cognitive decline following stroke. J Clin Exp Neuropsychol 20:503-517 